\title{
Controller Design for Electric Motor Derived Vehicle
}

\author{
Nitin Kumar Saxena, Sirak Gebrehiwot, Degu Mena \\ Wolaita Sodo University, Ethiopia
}

\begin{tabular}{l} 
Article Info \\
\hline Article history: \\
Received Mar 17, 2017 \\
Revised Mar 26, 2018 \\
Accepted Apr 25, 2018
\end{tabular}

Keyword:

DC permanent magnet motor Electric drive

PID (proportional-integral)

controller

\begin{abstract}
In this paper, proportional and integral based controller is designed for controlling the output voltage of battery. This battery is used for operating an electric motor derived vehicle. It has been represented that without any control mechanism the output voltage cannot be controlled and it will give a large deviation in output voltage in terms of error signal and that will decline the battery output current as a result battery power output will reduce and therefore the performance of electric motor derive vehicle will go down in terms of power and torque to derive vehicle. So, it is mandatory to maintain the output voltage of the battery and that can be achieved by a proper feedback control system. A PI based controller is designed and implemented for this electric motor derived vehicle in the present paper. Paper demonstrates how the results improve in presence of controller circuit for this electric motor derived vehicle.
\end{abstract}

Copyright $@ 2018$ Institute of Advanced Engineering and Science. All rights reserved.

\section{Corresponding Author:}

Nitin Kumar Saxena,

Wolaita Sodo University, Ethiopia

Email: nitinsaxena.iitd@gmail.com

\section{INTRODUCTION}

The traditional methods available in literature depicts that the rotational speed of motors can be popularly controlled by either controlling voltage or frequency or both by controlling V/f ratio. But, now days, derive based application concept is becoming more popular for supervising the speed of rotation of an electrical machine and therefore, any electrical machine can be precisely controlled by implementing the driving system with machine. All the researches have been more or less focused towards the application of environmental friendly renewable energy sources. These renewable energy sources can be used as primary energy source for deriving the prime mover. Transportation from one place to another place requires a lagre amount of energy that must be produced mainly from the different fossil fuels combustion for deriving the different vehicles. Electric vehicle are becoming more popular now a days due to the rapid depletion of fossil fuels, emission of enormous hazardous gases and continous inceresing fuel cost. The vehicles require energy for operating them and so, any renewable enegy source can be used as primary input energy source to derive the primemover first and then to derive the vehicle finally [1]. Derive systems have control systems in it that helps to adjust the required output from the electric vehicle. So, these derives can easily controlled the vehicle motion by adjusting the vehicle output through the optimization of control parameters and this is the main advantage of developing derive based vehicle. The simple definition for electric vehicles is that the system which controls the output charactesistics of any electrical machine is known as electrical drive. A Russian B. S. Akobi was the first who presented the electric derive for the world first time in 1838 before many years of industrial revolution that happens in 1870. In his initial tesing, he developed a storage battery operated DC electric motor to propel a boat. Presently, electric drives are being used widely in almost all types of large medium and even small scale industrial applications.

Electric derives are the assembly of one or more electric motors with control panels, the control panels get the signal through feedback and control the rotation of shaft of the motor. Basically electric drives works as prime movers for diesel engines, petrol enginers, gas turbines, steam turbines, hydraulic and electric motors. The use of advance control methods developes smoother, reliable, secure and fast control actions of 
these derives now days. So, the controlling techniques used with derive system should be more accurate and easy to acceptable. Along with industrial applications derives are also being used for domestic applications. Some commonly used domestic applications for these derive system are factories, transportation systems, textile mills, fans, pumps, motors, robots etc.

In this paper, a controller is designed for an electric vehicle. This electric vehicle is operated with the help of permanent magnet DC motor. A controller circuit is required in the system; this controller circuit generates commands through which input is produced for premannet magnet DC motor so that output characteristics of this DC motor (output power, shaft speed and torque on shaft) can be adjusted as per the requirement. A popular and fundamental controller that has been implemented in any system is proportionalintegral (PI) controller [2]. In this PI controller, the proportional gain constant $\mathrm{K}_{\mathrm{P}}$ and integral gain constant $\mathrm{K}_{\mathrm{I}}$ are adjusted for obtaining the desired results. The fundamental modelling for ideal PI controller is well explained and established in refs. [3] and [4] and the same is being used in this paper. The advance control methods are not incoperated in this present work but will be applied by the authors in their future research works and therefore, the advanced methods porposed in ref. [3] and [4] will be implemented for the same electric motor vehicle as discussed in this paper for authors' future research work. If the primary supply source for operating this permanent magnet DC motor is any kind of renewanle energy source such as photovoltaic operated electric vehicles, a supplement supply source is also required to improve the reliability of this electric vehicle. An electric battery is most preferable supplement supply source for these electric derive vehicles [5]. In present study, a simulink model is developed with fundamental PI controller technique and results are identified and investigated in terms of vehicle output power and efficiency for given torque and speed values as in ref. [6]. Mathematical expressions are presented and on their basis simulink models are designed for individual complements used in electric vehcilefirst and then a combined simulink diafgaram is developed haaving all the dpsecified compenets of this electric vehicle as in ref. [7]. All the simulink models are developed and assembeled in MATLAB software. This electric vehicle model developed in MATLAB simulink window is basically designed to elaborate the performance and energy flow in it but the study can be extended for energy conversion based studies in motoring and regenerative action modes of motor used in electric vehicle [8].

\section{MATHEMATICAL MODELLING FOR ELECTRIC MOTOR VEHICLE}

In this section, complete mathematics for electric motor vehicle is explained in details as in ref. [9]. The different important sections of this vehicle are being discussed separately in their respective subsections one by one for better understanding about the each component. The simulink models of respective components are also demonstrated in each section.

\subsection{Development of Power Model for Electric Vehicle}

Power output of the motor $P_{H}$ which is deriving this electric vehicle depends on torque $T_{r q}$ developed and rotor speed $\omega_{r}$ of the motor [10]. So, mathematically, power developed by the motor can be represented by Equation 1. The model is shown in the Figure 1.

$$
P_{H}=T_{r q} \times \omega_{r}
$$

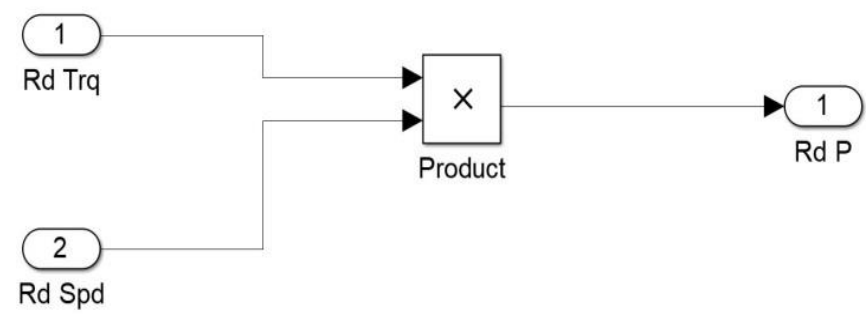

Figure 1. Model for developed power

\subsection{Motor Model for Electric Drive}

The model shows the Working of the motor by using the values of Torque \& Speed with the help of Motor resistance and inductance. Developed Voltage, current and Power [11], [12] is determined by the following Equations 2 to 5. 


$$
\begin{aligned}
& V_{H}=I R_{a}+L \frac{d i(t)}{d t}+E_{a} \\
& I_{H}=\frac{T_{r q}}{K_{m}} \\
& P_{H}=V_{H} I_{H} \\
& E_{a}=\omega_{r} K_{m}
\end{aligned}
$$

The Motor model is shown in the Figure 2

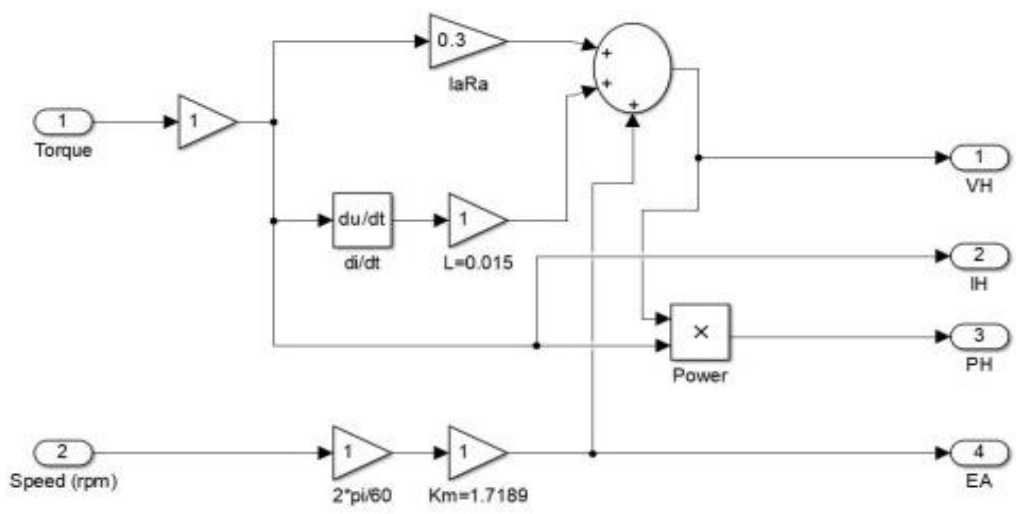

Figure 2. Motor model circuit

\subsection{Motor Controller Model for Electric Drive}

This Model shows the working of Motor controller of the electric drive by using the Values of $\mathrm{V}_{\mathrm{H}}$, $\mathrm{I}_{\mathrm{H}}$ and constant $K_{v a l}$. The values of $\mathrm{V}_{\mathrm{L}}$ and $\mathrm{I}_{\mathrm{L}}$ are determined by the Equations 6 and 7 as in ref. [13], [14].

$$
\begin{aligned}
& V_{L}=\frac{V_{H}}{K_{\text {val }}} \\
& I_{L}=K_{\text {val }} I_{H}
\end{aligned}
$$

\subsection{Battery Model}

In battery model, the value of the Battery error has calculated by the difference of actual voltage and the calculated voltage as is shown in Equation 8 [15]. Figure 3 shows motor controller model block. The battery model is shown in the Figure 4.

$$
B_{E R R}=E_{B}(\text { Actual })-E_{B}(\text { Calculated })
$$

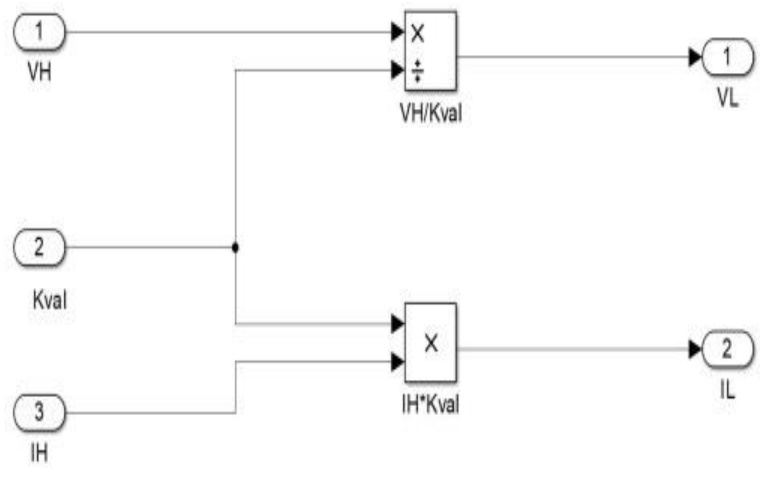

Figure 3. Motor controller model block

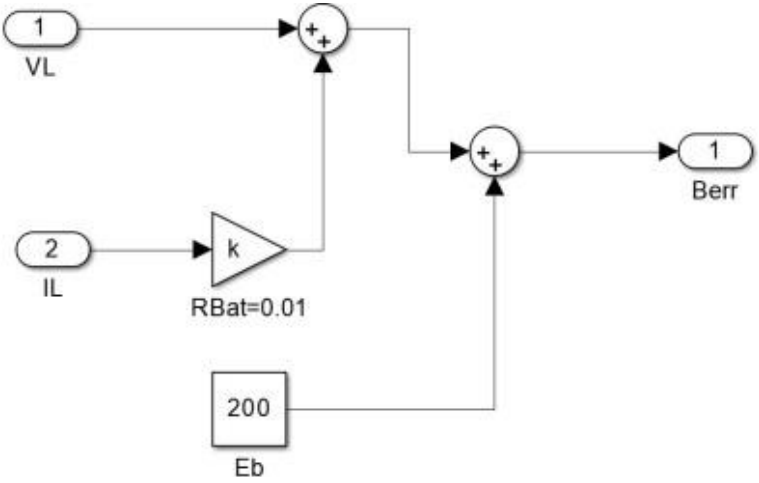

Figure 4. Battery model block 
Therefore, a complete simulation model by combining the all components described above in different subsections such as power model, motor model, motor controller model and battery model is shown in Figure 5. Ref. [16] gives basic idea to design and develop simulink model. The model shown in Figure 5 is an open loop model for motor derived vehicle as battery error i.e. the variation in output voltage form standard voltage is taken as output. To control the battery output voltage, a proportional and integral controller is represented in Figure 6 and this PI controller is implemented with system as shown in Figure 7. The error voltage signal $B_{E R R}$ is used as disturbance signal and gain constants for PI controller $\mathrm{K}_{\mathrm{P}}$ and $\mathrm{K}_{\mathrm{I}}$ as shown in Figure 6 are used as control variables. The PI controller accepts the $B_{E R R}$ signal from the battery model and use $\mathrm{K}_{\mathrm{P}}$ and $\mathrm{K}_{\mathrm{I}}$ to calculate gain $K_{v a l}$ that is used by the motor controller according to [17].

$$
K_{v a l}=(k p \times s \times k i) \times B_{E R R}
$$

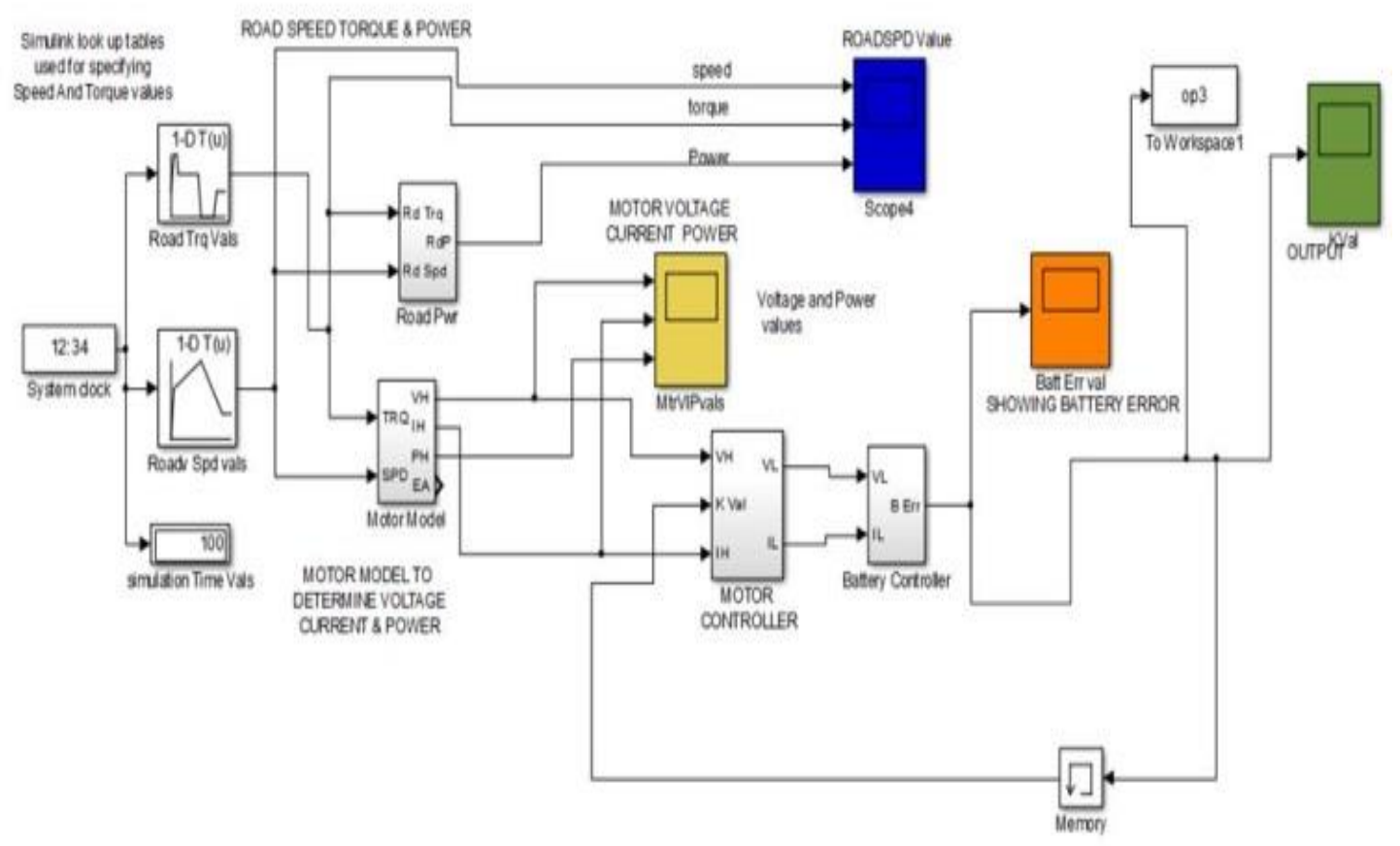

Figure 5. Electric drive model without PI controller

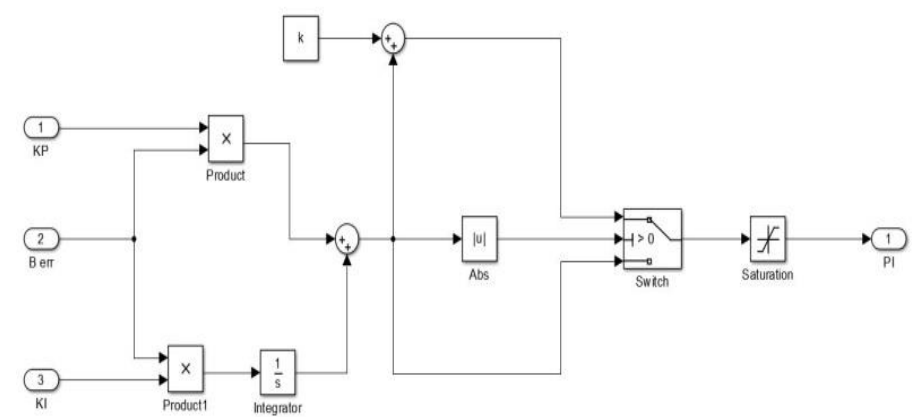

Figure 6. PI Controller Model block 


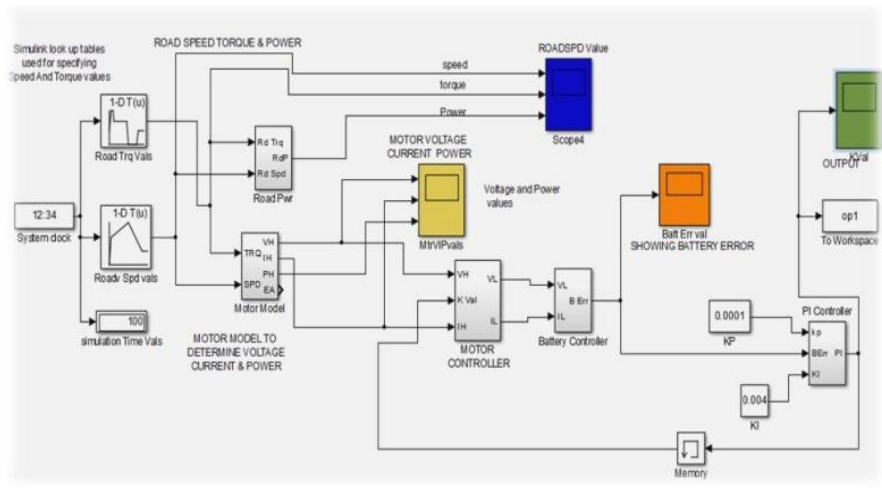

Figure 7. Electric drive motor with PI Controller

\section{RESULTS AND DISCUSSIONS}

In this paper, the results show the role of controller design for electric motor electric vehicle. The fundamental model for vehicle having motor battery and controller is explained in this paper with the help of mathematical expression and their corresponding simulink model. Results are shown in terms of graph for variation of torque, variation of speed, variation of power, variation of voltage, variation of current, and variation of power for battery motor and vehicle. Some results are discussed in this section.

The variations for road torque, road speed and power with respect to time is presented in the Figure (8) to (9) respectively. Power developed in the motor as in given Equation 1 is a fubnction of the speed and torque. The dc motor provides output power in the direction same as rotor direction if positive speed and tirque values are taken for the case of normal motoring mode. However, dc motor starts working as a generator i.e. its output power becomes negative when the motor torque iand speed both are in opposite direction and this case is known as motor regenerating operation mode.

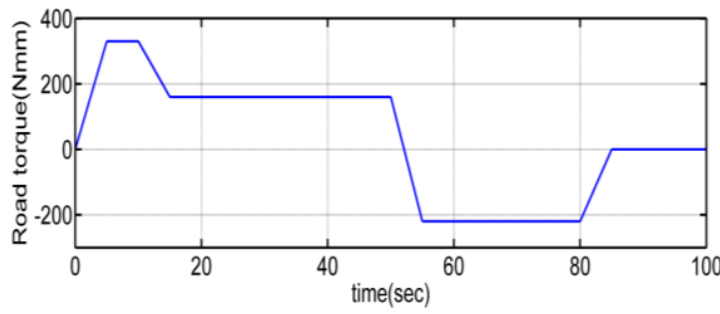

Figure 8. Representation for variation of vehicle torque with respect to time

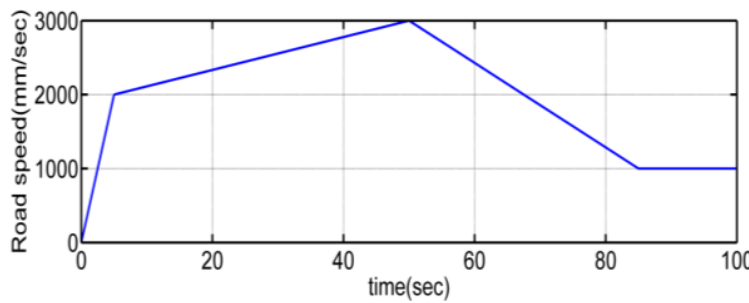

Figure 9. Representation for variation of vehicle speed with respect to time

Figure 10 to 12 repersents the motor voltage, current and power with respect to time. The motor draws power for the battery. Comparison between Figure 8 to 12 describes that the curves of motor voltage and vehicle speed are following to each other. Similarly, the vehicle torque and motor current curves are also following to each other. This means vehicle torque can be developed according to the requirement by adjusting motor current and vehicle speed can be adjusted with the helop of motor volatge. Figure 13 presents the power variation for motor which is evaluated using voltage and current values as in Figure 11 and 12.

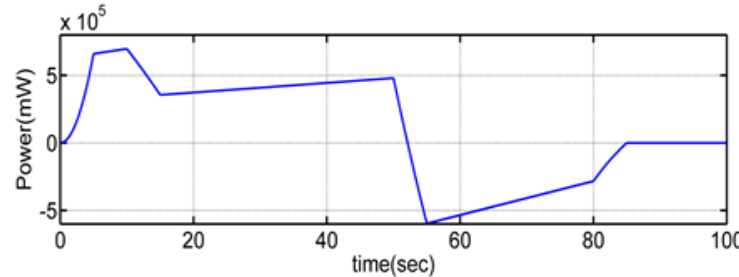

Figure 10. Representation for variation of vehicle power with respect to time

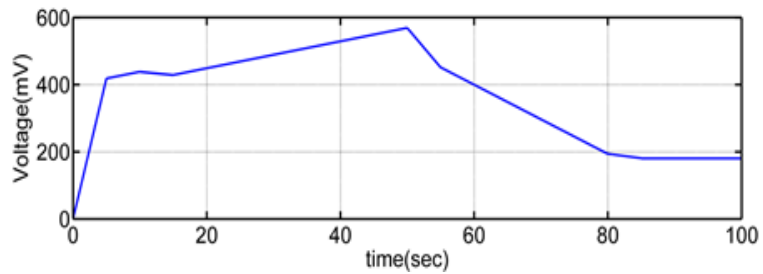

Figure 11. Representation for variatiion of Voltage with respect to time 


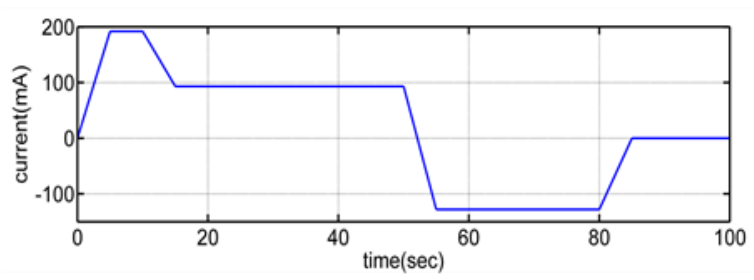

Figure 12. Representation for variation of current with respect to time

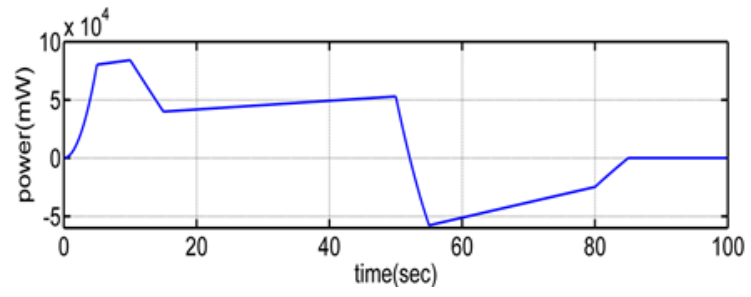

Figure 13. Representation for variation of power with respect to time

In normal operating condition, both current and voltage are positive, the dc motor provides torque in the direction same as the direction of rotation and finally output power is supplied to the load. This is normal motoring operation. However when motor current is opposite in respect to voltage then motor behaves as generator and current flows back in to the battery. The battery voltage error is calculated with the help of actual voltage and calculated voltage .The difference of the two provides the value of battery error voltage that is denoted $B_{E R R}$. The graph shows the variation of battery voltage error with respect to time in the Figure 14.

This difference $B_{\text {ERR }}$ is used as control variable to get final disturbance variable of voltage by adjusting $\mathrm{K}_{\mathrm{P}}$ (proportional) and $\mathrm{K}_{\mathrm{I}}$ (integral) gain constants for PI controller as state variables. The battery model shown in the Figure 14 is followed to calculate the value of battery error voltage. The motor controller gain $\mathrm{K}_{\mathrm{val}}$ has been determined by the output as shown in the PI controller model. The simulation result for the value of the controller gain $\mathrm{K}_{\mathrm{val}}$ is presented in Figure 15. The controller gain is directly related the motor speed i. increasing with increase and decreasing with decrease. The power gets improved by using the gain controller.

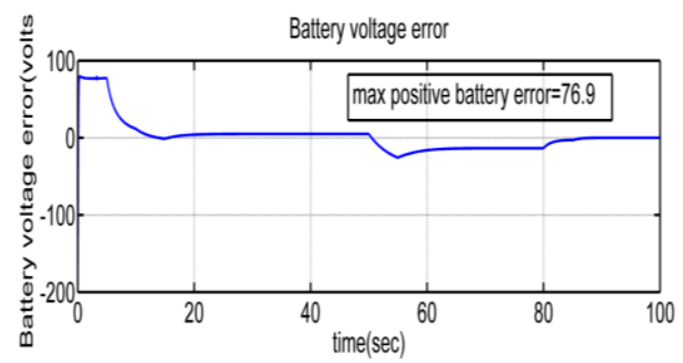

Figure 14. Representation for variation of battery voltage error with respect to time

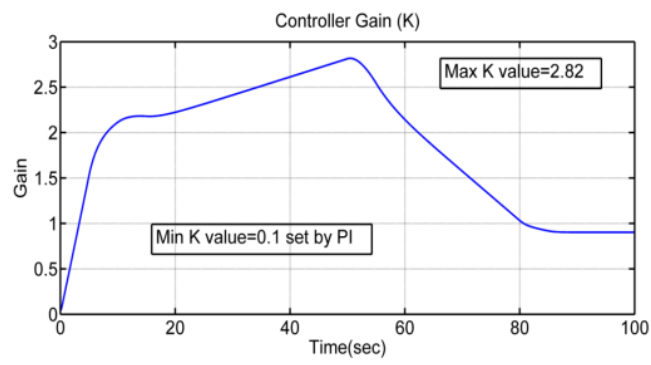

Figure 15. Representation for the value of controller gain $\mathrm{K}$ value

The initial starting value of gain is set as 0.1 theough preset setting in integral block (1/s block) of the controller. This value is set in the simulation by opening up the $1 / \mathrm{s}$ block. Initial Condition on the integration block sets to reduce the possibile simulation error for algebraic loop. A divide by zero operation of algebra forms an algebraic loop when the simulation is trying to solve the set of linear equations.

By comparing the graph of the Figure 14 (Battery Error Voltage without PI Controller) and Figure 15 (Battery error Voltage with PI Controller), it can be concluded that the value of the error voltage gets reduced by using a PI controller. This error correction signal is either in proportion or in integral relation to the system. An error correction signal is provided by the Proportional - Integral Controller (PI). The fundamental mechanism of the proportional signal is to redpond for system changes and of the integral signal is to reduce steady sate (constant) errors in the system. The Kp and Ki controller constants are determined by trial and error while observing the magnitude and response of the Berr signal. 


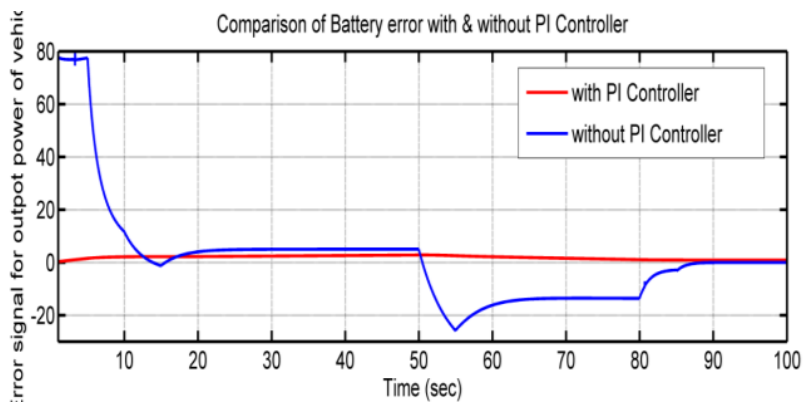

Figure 16. Comparison of the Battery error Voltage $\left(\mathrm{B}_{\mathrm{ERR}}\right)$ with and without PI Controller

\section{CONCLUSION}

The work carried out in this paper represents how proportional and integral based controller designed for controlling the output voltage of battery improves the performance of electric motor vehicle. It has also been demonstrated that without any control mechanism the output voltage cannot be controlled and it will give a large deviation in output voltage in terms of error signal but a properly designed control mechanism improves the battery performance and therefore vehicle can be operated with improved torque and power. The future work may be done for selecting the gain constants for PI controller with the help of advanced tuning methods.

\section{REFERENCES}

[1] W. Kempton, and J. Tomic. Vehicle-to-grid power implementation: From stabilizing the grid to supporting largescale renewable energy. Journal of Power Sources, 2005; 144(1): 280-294.

[2] H. P. Wang and Y. T. Liu. Integrated design of speed sensorless and adaptive speed controller for a brushless DC motor. IEEE Transaction of Power Electron. 2006; 21: 518-523.

[3] Nitin Kumar Saxena and Ashwani Kumar. Reactive Power Control in Decentralized Hybrid Power System with STATCOM Using GA, ANN and ANFIS Methods. International Journal of Electrical Power and Energy Systems (IJPEDS). 2016; 83: 175-187.

[4] Nitin Kumar Saxena and Ashwani Kumar. Reactive power compensation of isolated hybrid power system with load interaction using ANFIS tuned STATCOM. Frontiers in Energy. 2014; 8(2): 261-268.

[5] Mi. Masrur and Gao. Hybrid Electric Vehicles, New York, Wiley, 2011.

[6] M. Ehsani, M. Falahi and S. Lotfifard. Vehicle to grid services: Potential and applications. Energies, 2012; 5: 4076-4090.

[7] W. Kempton, and J. Tomic. Vehicle-to-grid power fundamentals: Calculating capacity and net revenue. Journal of Power Sources. 2005; 144: 268-279.

[8] E. Larsen, K. C. Divya, and J. Ostergård. Electric Vehicles for Improved Operation of Power Systems. Proceedings of IEEE Energy 2030, Atlanta, 2008.

[9] Saurabh, Model-Based Design for Hybrid Electric Vehicle Systems, Paper 2008-01-0085, www.mathworks.com.

[10] Herniter, Combining Passion with Fundamentals - Applying Model-Based Design to Education, Paper 2008-011292, www.mathworks.com.

[11] B.H. Bakken and O.S. Grande. Automatic generation control in a deregulated power system. IEEE Transactions on Power Systems, 1998; 13(4): 1401-1406.

[12] Bo Long, Shin Teak Lim, Ji Hyoung Ryu and Kil To Chong. Energy-Regenerative Braking Control of Electric Vehicles Using Three-Phase Brushless Direct-Current Motors. Energies. 2014; 7: 99-114.

[13] Thomas D. Gillespie. Fundamentals of Vehicle Dynamics. SAE International. 1992; 110-115.

[14] Gerrit Kadijk and Norbert Ligterink. Road load determination of passenger cars. TNO report. 2012; 1-32.

[15] F. Lu, C. C. Liu and C. J. Wu. Effect of battery energy storagelsystem on load frequency control considering governor dead band and generation rate constraint. IEEE Transactions on Energy Conversions. 1995; 10(3): 555561.

[16] Sachin Sharma, Alok Pandey and Nitin Kumar Saxena. Modeling of Six Pulse Voltage Source Inverter based STATCOM with PWM and Conventional Triggering. Indonesian Journal of Electrical Engineering and Informatics (IJEEI). 2017; 5(2): 108-116.

[17] Iqbal Husain. Electric and Hybrid Vehicles Design Fundamentals. CEC Press. 2010. 